\title{
Research progress on space charge characteristics in polymeric insulation
}

\author{
Yibo Zhang* $\star$, Thomas Christen ${ }^{\dagger}$, Xing Meng*, Jiansheng Chen* and Jens Rocks ${ }^{\dagger}$ \\ *ABB (China) Limited, Corporate Research, UBP B6L1 10 Jiuxianqiao Lu \\ Chaoyang District, Beijing 100015, P. R. China \\ ${ }^{\dagger} A B B$ Schweiz AG, Corporate Research, Segelhofstrasse 1K, CH-5405 \\ Baden 5 Dättwil, Switzerland \\ tboveri-yibo.zhang@cn.abb.com
}

Received 27 February 2015; Revised 18 January 2015; Accepted 21 January 2016; Published 10 March 2016

\begin{abstract}
Due to their excellent electrical insulation properties and processability, polymer materials are used in many electrical products. It is widely believed that space charge plays an important role for the electric field distribution, conduction, ageing, and electric breakdown of polymeric insulation. This paper reviews measurements and characteristics of space charge behavior which mainly determined by the pulsed electro-acoustic (PEA) measurement technique. Particular interests are the effects of the applied voltage, the electrodes, temperature, humidity, microstructure, additives, and filler materials on accumulation, distribution, transport, and the decay of space charge in polymeric materials. This review paper is to provide an overview on various space charge effects under different conditions, and also to summarize the information for polymeric materials with suppressed space charge and improved electrical behavior.
\end{abstract}

Keywords: Polymeric insulation; space charge; PEA; nanocomposite.

\section{Introduction}

A great number of polymers like polyethylene (PE), polypropylene (PP), polyimide (PI), etc are used in insulation systems because of their excellent electrical insulation properties and their flexible and convenient processability. Due to low price and abundance in raw materials, particularly polyolefin materials like PE and PP take up a great portion in many applications, like cable insulation and metallized film capacitors.

Long term stability of insulation materials is critical for the safety operation of high voltage apparatus, especially in the high voltage direct current (HVDC) applications. In particular, a predictable electric behavior in high electric fields and in a large temperature range is important. This is a challenge in HVDC applications because of the danger of space charge formation, which can strongly influence electric conduction, ${ }^{1-3}$ ageing, ${ }^{2,4-7}$ and breakdown ${ }^{8-11}$ of the insulation. ${ }^{10,12}$ The unwanted charges are harmful because they may accumulate and lead to electric field enhancements with detrimental consequences. ${ }^{12}$ Therefore, the pulsed electroacoustic (PEA) method is widely used for studying the space charge distribution, and how its behaviors like accumulation, distribution, transportation, and decay are influenced by the electric stress, voltage poling-time, electrodes, temperature, humidity, additives, filler content, and micro-structural morphology. However, note that PEA space charge measurement is useful not only for HVDC materials but also for the characterization of insulation in general (for DC and AC applications), e.g., in the context of ageing. ${ }^{13,14}$
Space charge characteristics obtained by the PEA method are compared and summarized in this paper, mainly but not exclusively for polyolefin and epoxy resin. On one hand, we provide information helpful for comparing space charge results under various different conditions, and for defining appropriate measurement conditions of own experiments, in order to better estimate the behavior of internal charges, ${ }^{15}$ monitor electrochemical migration, ${ }^{16}$ and ageing ${ }^{17}$ in our polymeric insulation. On the other hand, the summarized results may also be a guide for the development of optimized filled polymer materials with respect to suppressing the harmful space charge. Last but not least it provides an overview on some current knowledge and part of the extensive appropriate literature on space charge of polymeric insulation.

\section{The PEA Method}

Invented by Maeno in 1980s, ${ }^{18}$ the PEA method has been the most popular one among a number of space charge measurement techniques ${ }^{19}$ and seems well suited for specimens with thicknesses of some hundreds of microns. When a pulsed electric field is applied to a specimen that has internal charges, the consequent electric forces generate acoustic waves starting at the location of the charges, propagating with sound velocity through the specimen, and are then detected by a piezoelectric sensor attached to an electrode. The resulting signal coming from all locations in the sample and

This is an Open Access article published by World Scientific Publishing Company. It is distributed under the terms of the Creative Commons Attribution 4.0 (CC-BY) License. Further distribution of this work is permitted, provided the original work is properly cited. 


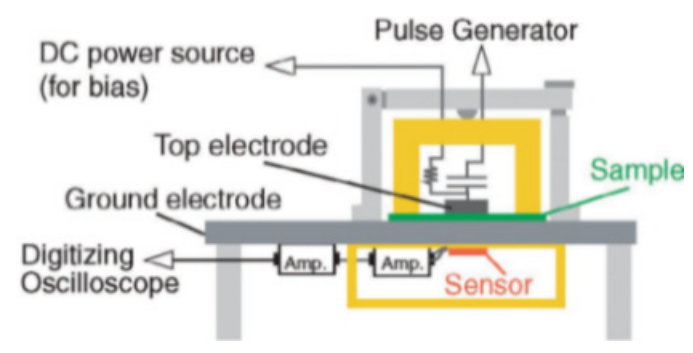

(a)

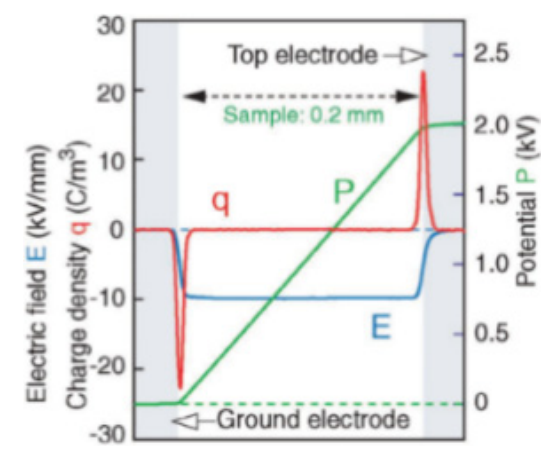

(b)

Fig. 1. (Color online) (a) A typical schematic diagram of a PEA system, (b) typical signals from a polymer sheet under a dc electric field. $^{20}$

arriving at different times is then displayed on the oscilloscope. By this the space charge distribution can be measured quantitatively in a nondestructive manner. Figure 1(a) shows a schematic of a PEA system. Figure 1(b) shows an ideal PEA measurement result of a film without internal space charge. Injection of charges is restricted to surface regions as shown in the red curve (q), from which the internal field and the potential can be calculated with the help of the Poisson equation.

\section{Influence of Experimental Conditions}

An important question is the effect of the PEA experiment parameters, including the experimental environment conditions, on the space charge measurement. ${ }^{21}$ On the one hand, it helps to find the optimal parameter values for material characterization. On the other hand, it supports to understanding of the space charge behavior in real applications, particularly the dynamics of space charge under field, and the connection with insulation ageing and breakdown.

\subsection{Electric field dependence}

The applied voltage, or the electric field, can play a role in two ways, namely via charge injection from the contacts and via charge transport in the bulk. Thus, the polarity, strength, and poling time of the electric field will have significant impact on the space charge profiles measured by PEA.

\subsubsection{Electric field polarity}

In general, charge polarity symmetry is broken because the positive and negative carriers (electrons/holes, anions/ cations) behave generally differently, both in the bulk (mobility, trapping) and at the electrode contact (injection energy barrier, tunneling trap states). Depending on these properties, either homo-charge (= space charge with polarity of nearby electrode) or hetero-charge (= space charge with other polarity of nearby electrode) can form. On the other hand, often electron motion, either injected to or extracted from polymers, e.g., PP, ${ }^{1,22} \mathrm{PE},{ }^{22,23}$ and silicone rubber, ${ }^{24}$ is found, which is attributed to the higher mobility.

Concerning polarity, it is worth to mention the "mirroreffect", 25,26 according to which a polarity change leads to the mirror-imaged space charge distribution, which has sometimes been reported and measured in XLPE. This observation is in contradiction to the general polarity symmetry breaking of the carriers; however, one can explain it, e.g., with the special assumption that the reason for charging is a spatially nonuniform conductivity (or permittivity), be it due to byproduct distribution or due to an inhomogeneous material structure. Also, the dipolar polarization after stressed might provide contributions to the space charge response.

\subsubsection{Space charge transition at breakdown}

Under a given electric field, the space charge profile can be measured during polarization (voltage-on) and depolarization (voltage-off) process, including the breakdown process. ${ }^{27,28}$ Usually, it is assumed that the purely capacitive charge associated with the external voltage is subtracted. The measurement result of space charge changing provides information on the polarity, the position of charge accumulations, and the movement of charge packet. There exists a large variety of space charge behavior among different polymeric insulation materials, ${ }^{27}$ even among PP and its copolymers with different catalyst systems show different results. ${ }^{1}$ If the time intervals are narrowed, contiguous data for space charge dynamics can be obtained. Figure 2, obtained by 3-H PEA system ("3-H" means the system can measure space charge profiles under high voltage, at highrepetition and with high spatial resolution ${ }^{20}$ ), shows an example. ${ }^{20}$ In this experiment, a large voltage was applied such that breakdown occurred, at which the electrodes were immediately (within $0.1 \mathrm{~s}$ ) shorted, and the space charge was monitored. During voltage-on the formation, location, and movement of the positive charge packet with time can be observed, as well as the interesting charge behavior after breakdown.

\subsubsection{Electric field strength}

Space charge behavior in polymeric insulation also depends on the applied field. It is often observed that a finite threshold 


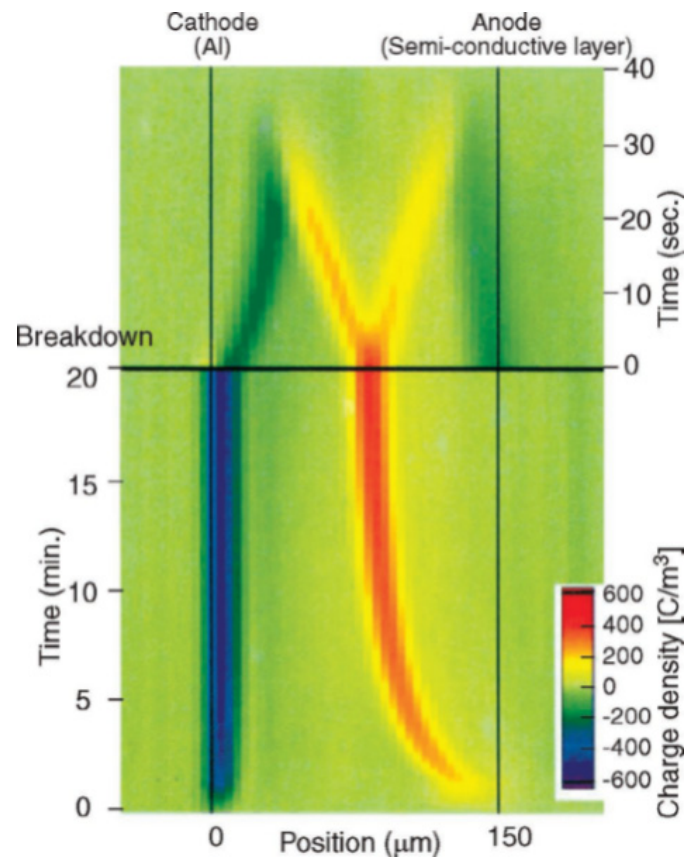

Fig. 2. Time dependence of space charge profiles in PE specimen at $50 \mathrm{kV}$. Positive charges are injected and move towards the cathode, and then they separate into two parts after breakdown, finally disappearing within tens of seconds. ${ }^{20}$

field exists that is associated with the onset of space charge. We remark that from a simple theoretical point of view, one expects that at low voltage ohmic conduction predominates, while at higher voltage space charge limited conduction with homo-charge may be expected if conduction is unipolar; hetero-charge may be expected when the electrode contact behaves partially blocking. Nevertheless, reality is not that simple. A typical value for the (average) onset fields is 10 $30 \mathrm{kV} / \mathrm{mm} .{ }^{3,29,30}$ Figure 3(a) shows the charge distribution at a field below and above threshold field $\left(E_{\mathrm{T}}\right)$ in epoxy resin after $20 \mathrm{~s}$ of volt-off. ${ }^{31}$ For fields below $E_{\mathrm{T}}$ space charge is absent (cf. also red curve in Fig. 1). Above the $E_{\mathrm{T}}$, a homocharge packet appears in the vicinity of the lower electrode. Figure 3(b) displays a threshold field separating into two regimes defined in field larger than $10 \mathrm{kV} / \mathrm{mm}$. Reference 36 provided information on the specific relation between space charge distribution and electric field. ${ }^{36}$ In the range of $5-10 \mathrm{kV} / \mathrm{mm}$, the space charge profiles exhibit no notable difference, because there is only surface charge on the electrode. When the electric field strength is raised to 15 and $20 \mathrm{kV} / \mathrm{mm}$, it was seen that the charge peaks across the interface between the electrode and the specimen move to the specimen bulk, indicating that charges at the electrodes moves forward the bulk, and also charges in the bulk are redistributed inside.

The threshold field of epoxy resin insulation is not always the same, and is varying with epoxy resin type, temperature, ${ }^{32}$ humidity, ${ }^{31,33}$ degree of ageing, ${ }^{31}$ and electrode materials. $^{34,35}$

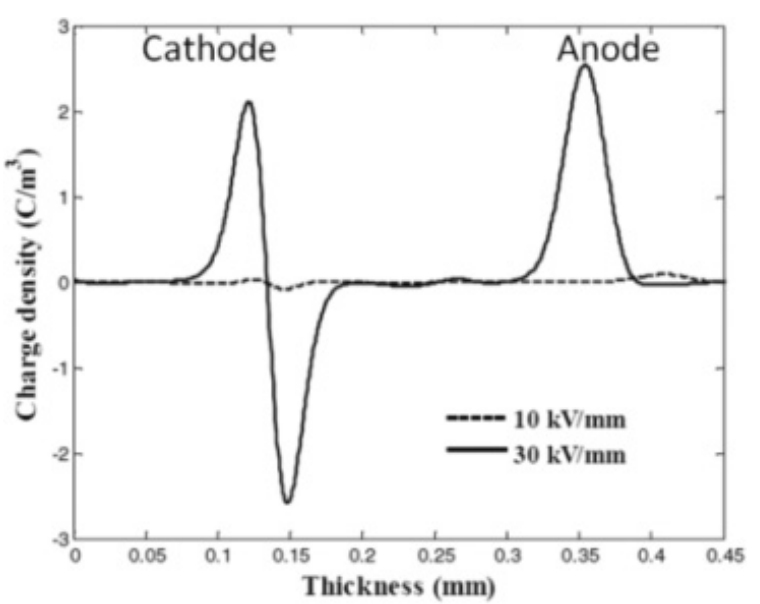

(a)

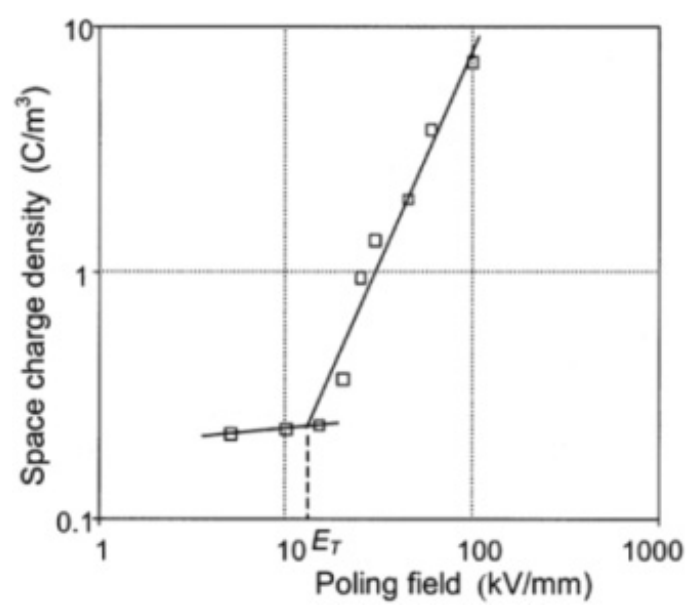

(b)

Fig. 3. (a) Spatial distribution of charge below and above $\mathrm{E}_{\mathrm{T}} \cdot{ }^{31}$ (b) Space charge density versus poling field. The threshold field for space charge accumulation is indicated. ${ }^{29}$

Beyond the mentioned first threshold field value, there may exist other threshold field values where the space charge behavior becomes even more complex, like the emergence of traveling space charge packets in the form of solitary waves. The threshold field for traveling packets characterizes sometimes at the same time a threshold for the onset of electro-luminescence. ${ }^{36}$

The 3-H PEA system allowing real-time space-charge observations makes it possible to measure charge packet dynamics, ${ }^{9}$ as shown in Figs. 4(a) and 4(b). The negative hetero-charge accumulation near the anode forms after injection from the cathode and subsequent drift with approximate velocity of $500 \mu \mathrm{m} / \mathrm{h}$; the authors guess that for positive charges a similar process holds, but with more diffusive transport. Figure 4(b) shows space charge profiles in $\mathrm{SiO}_{2}$ filled epoxy resin just before breakdown. With increasing applied field alternating regions of positive and negative charges occur, which increase in density. This may be due to 


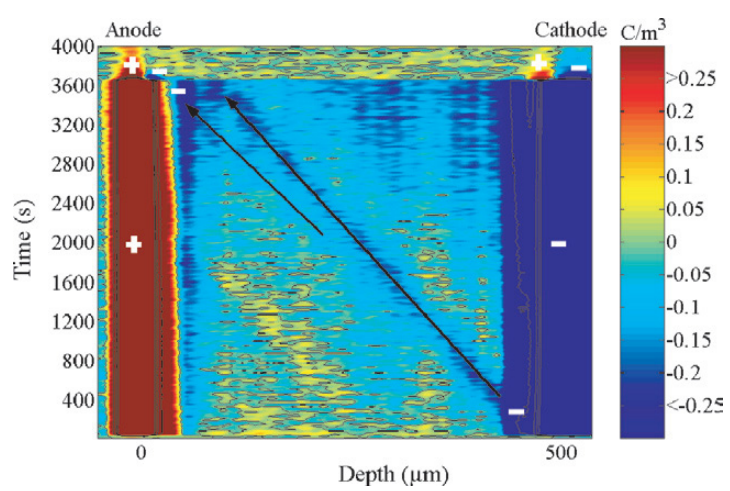

(a)

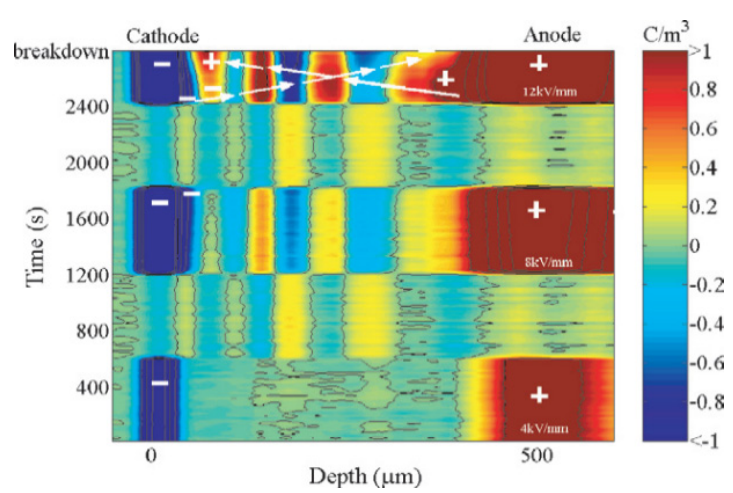

(b)

Fig. 4. (a) Space charge density in a pure epoxy resin sample under $40 \mathrm{kV} / \mathrm{mm}$ and voltage-off after $3600 \mathrm{~s}$. The diagonal arrow indicates the progression of a front of negative space charge from cathode to anode. (b) Space charge evolution in a $\mathrm{SiO}_{2}$ filled epoxy resin sample just before breakdown. Voltage-on and voltage-off periods last for $600 \mathrm{~s}$. Cathode (anode) at about $x=0(x=500 \mu \mathrm{m}){ }^{9}$

the accumulation of space charge in the interfacial region of $\mathrm{SiO}_{2}$ grains. At about $12 \mathrm{kV} / \mathrm{mm}$ breakdown happens when hetero-charges accumulate while homo-charges accumulation disappear, because hetero-charges lead to large field enhancements.

\subsection{Electrodes}

When a PEA measurement is carried out on an insulation sample, the shape, material and thickness of the electrodes, as well as the contact condition have a bearing on the charge injection and signals from PEA system. One has to keep in mind that (for DC issues) it is always the insulation-electrode system as a whole that must be considered, and it is often meaningless to make separate statements on the insulation bulk material alone. The dependence of the formation and injection of space charge on the electrode materials (metals, semicon) has been investigated in many works. $8,10,17,29-51$

Although various different electrode shapes have been considered in PEA systems, sphere-plane, ${ }^{11,42}$ needle-plane, ${ }^{38}$ line-plane, ${ }^{24}$ and plane-plane ${ }^{22,39-45}$ electrodes are widely

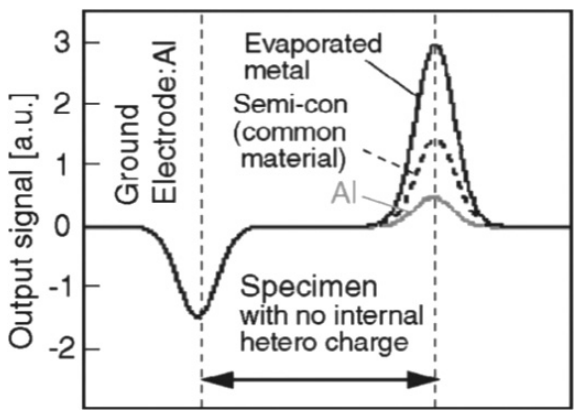

Fig. 5. The output signals obtained when the top electrode material varies. $^{20}$

used nowadays. While the ground electrode is always a plate, the top electrode may take various forms. It is possible to measure PEA on cylindrically shaped samples (model cables). ${ }^{48,49,51}$

Usually semi-conductive material is chosen as top electrode in PEA measurement systems, because the amplitude of signals from top electrode is what is to be expected according to zero net charge, as is seen in Fig. $5 .^{20}$ Electrodes of samples may be evaporated $\mathrm{Al}, \mathrm{Cu}, \mathrm{Au}, \mathrm{Ag}$, and $\mathrm{C}$. The evaporated electrodes receive energy from the semi-conductive material and on the other hand they transfer energy to the sample. Compared to unevaporated sample, carrier injection from evaporated sample seems to be suppressed, ${ }^{9,22}$ and the thicker the evaporated layer is, the more carrier can be prevented from injection. ${ }^{22}$ However, charge injection behavior of PI is quite different from those of LDPE, epoxy, and PP. Here the injection was enhanced by metal evaporation with the rear semi-conductive electrode, but not by metal evaporation with the Al-plate electrode. ${ }^{40}$ Compared with a plate that is mechanically connected to the specimen, the evaporated electrode shows much less carrier injection into $\mathrm{LDPE}^{39}$ and $\mathrm{PP}^{1,11}$ due to the interfacial condition between specimen and electrode.

The carrier injection and accumulation for different electrode materials differ. Among epoxy specimens sputtercoated with different metallic electrodes, $\mathrm{Au}, \mathrm{Ag}$, and $\mathrm{Cu}$, the one with Ag electrodes show largest space charge density and the least space charges accumulation threshold, probably because $\mathrm{Ag}$ has the lowest work function among them (see Table 1). It is speculated the capacity of charge injection of $\mathrm{Al}$ is better than that of $\mathrm{Ag}$ according to an even lower work function value. Else, after being electrically pre-stressed, LDPE with an $\mathrm{Au}(+)-\mathrm{Ag}(-)$ electrode pair accumulates more hetero-charges than that with $\mathrm{Au}(-)-\mathrm{Ag}(+)$ electrode pair. ${ }^{42}$ The space charge distribution difference is related to electron and (or) hole injection efficiency for different electrode materials. So is charge trapping depth and trap controlled mobility. ${ }^{34,42}$ Nevertheless, the diversity of observations makes it obvious that further research is still needed.

Table 1 gives a list of metals, which are often used for electrode materials, ${ }^{34,35}$ together with their corresponding 
Table 1. List of electrode metals and their work function. ${ }^{20}$ Graphite is given as it is related to semicon material.

\begin{tabular}{lc}
\hline Metal & Work function $(\mathrm{eV})$ \\
\hline $\mathrm{Al}$ & 4.08 \\
$\mathrm{Ag}$ & 4.26 \\
$\mathrm{Cu}$ & 4.65 \\
$\mathrm{Au}$ & 5.10 \\
$\mathrm{Graphite}$ & 4.82 \\
\hline
\end{tabular}

work function. Graphite is also listed as it might give a hint on the work function of carbon black in semicon material (but note that the properties of carbon black may strongly depend on the carbon black type and are usually not simply related to graphite). An important effect of the semicon may be the diffusion of additives in or out of the insulation material, which may lead to gradients of the conductivity and thus to space charge, which might be a reason why typically semicon electrodes lead to more pronounced space charge than evaporated metals (which might even act as diffusion barriers). But also the carbon black particle size may play a role. $^{50}$

Because electrode contacts have a big influence, the different requirements on contacts in the PEA measurement (acoustic transmission/reflection properties, etc.) and in the applications (minimized aging, high electric strength, diffusion barrier, etc.) may make a one-to-one material characterization for an application difficult. Charge injection from evaporated metallic electrodes seems to be weaker than for pressed contacts or (co-extruded, vulcanized) semicon contacts that are chemically bound. Needless to say that one should in any case select for characterization of the appropriate contact system as close as possible to the system of the real application, instead of using just something.

\subsection{Temperature}

With the increase of temperature, the thermal motion of the mobile units in polymer chains increases, and so do the mobility and free volume. Defects or traps change with it. Together with the thermal motion of the carriers, a change in electric conduction and space charge behavior may result. ${ }^{1,52-54}$ See Fig. 6 as an example for change density changes under different temperature.

The relationship between space charge phenomena and glass transition temperature $\left(T_{g}\right)$ of epoxy resin has been investigated. ${ }^{54-57}$ Electric field distortion caused by injected charges was more likely being observed at lower temperature $\left(<T_{g}\right)$, for higher temperature $\left(>T_{g}\right)$ increases the carrier mobility and thus space charge disappears rather than accumulates. ${ }^{55}$

Chen et al. ${ }^{56,57}$ deem that while homo-charges are accumulated in epoxy resin at lower temperature $\left(<T_{g}\right)$,

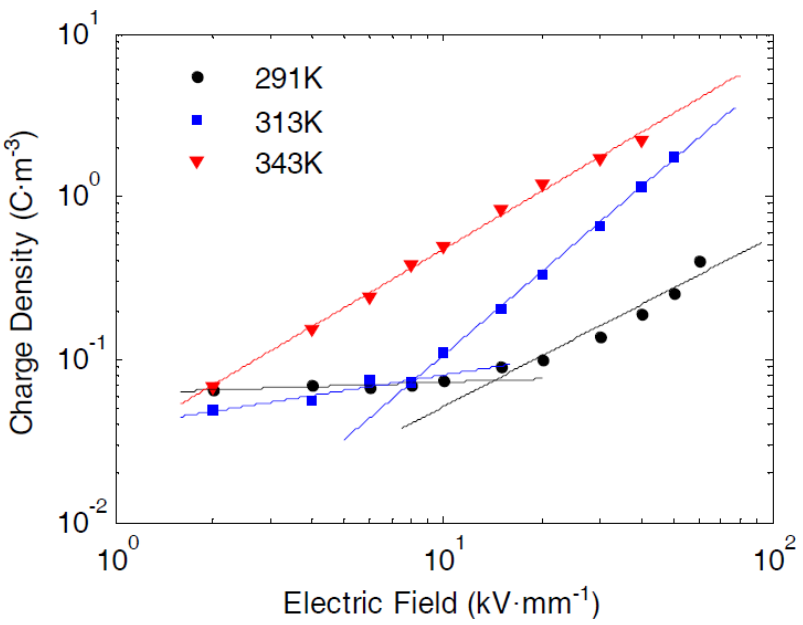

Fig. 6. Charge density (12 s after the voltage-off) versus poling field at different temperatures for epoxy resin specimens. ${ }^{5}$

hetero-charges form in epoxy resin at higher temperature $\left(>T_{g}\right)$. The argument is that the high elastic state supports ion formation, which has hetero-charge as the consequence if the electrode behaves blocking for the arriving ions (i.e., if the electro-chemical neutralization of the ions by the electronic current is slower than the ion current). The dissociation of impurities and then moving at $T_{g}$ gives rise to the heterocharges. The temperature dependence of the space charge distribution and transportation in epoxy resin has been confirmed. ${ }^{31,32}$

Charge packets are only observed in LDPE at lower temperature $\left(<30^{\circ} \mathrm{C}\right)$ but not at higher temperature $\left(>50^{\circ} \mathrm{C}\right){ }^{58}$ Possible explanations are: (1) that the packets move too fast to be detected; (2) charge is screened because of the increased intrinsic carrier density. The velocity of the space charge in PP is not that fast as in LDPE. ${ }^{52}$ Mizutani et al. found that the largest amount of space charge in PP was detected at $40^{\circ} \mathrm{C}$, instead of $23^{\circ} \mathrm{C}$ or $60^{\circ} \mathrm{C}^{1,27}$ At $23^{\circ} \mathrm{C}$, charge injected from ground electrodes is dominant, while charge injected from the upper electrode is dominant with rising temperature. Elevated temperature is good for charge injection as well as conduction, so the charge amount detected by PEA is the net result, which depends on the insulation itself and temperature. Apart from the former example, the conclusion was also illustrated with polycarbonate (PC). ${ }^{59}$

We emphasize that in most of our applications temperature gradients are present. It is thus important to know the space charge behavior under such conditions. Clearly, space charge must already be expected by the highly nonuniform conductivity, which occurs due to the strong T-dependent and thus nonuniform conductivity. Reports on PEA measurements in temperature gradients exist in the literature. ${ }^{51}$

\subsection{Humidity and inherent moisture}

Polymeric insulation always contains a certain amount of humidity. An increase in humidity may lead to a larger charge 


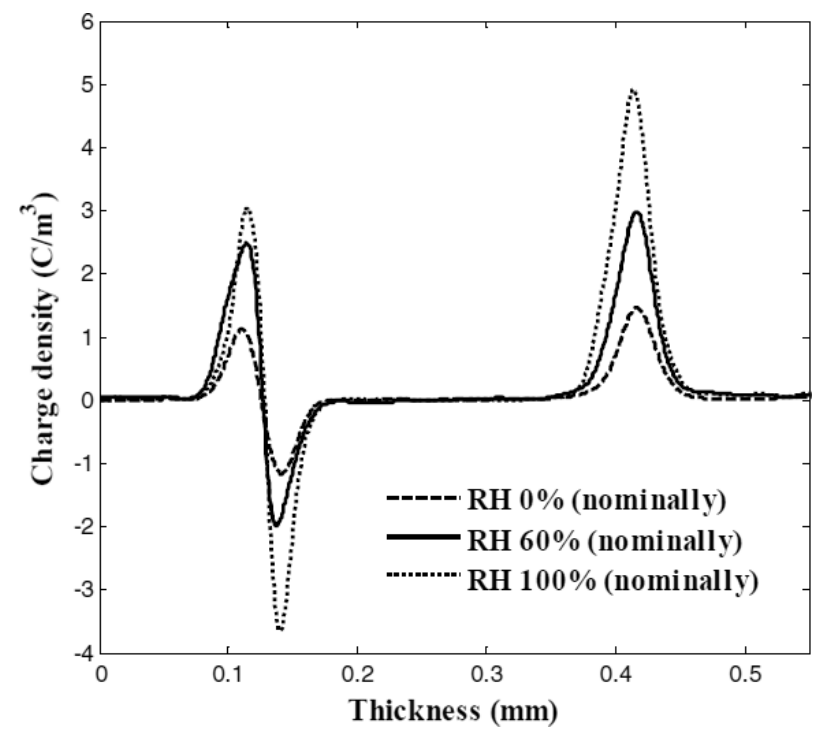

Fig. 7. Space charge distribution for different $\mathrm{RH}$ condition (aged at different humidity conditions for 15 days) measured at $40 \mathrm{kV} / \mathrm{mm}$ after $20 \mathrm{~s}$ from volt-off. ${ }^{31}$

density. ${ }^{31,32,59-62}$ This generally accepted conclusion is confirmed by Fig. 7. Aragoneses et al. explained that the charge accumulation on the surface is attributable to the presence of moisture, which generates new trap centers in the surface of the material and making the accumulation pass into the bulk. ${ }^{63}$ Therefore, the transit speed of charge packets can also be enhanced for polymeric samples with moisture. ${ }^{63,64}$ Montanari and Palmieri owed the disappearance of the charge packet occurring at very high fields under large relative humidity to the increased availability of shallower traps. ${ }^{65}$ Another noteworthy conclusion is that electric field threshold also decreases with increasing relative humidity. $33,34,65,66$

For polymeric composites with fillers, Zou et al. brought forward a "water shell" model to describe the extra water surrounding the $\mathrm{SiO}_{2}$ in polymeric nanocomposite (see Fig. 8). The percolation of water shells enhances here the effective mobility of carriers in the epoxy matrix. ${ }^{66}$ The thickness of the water shell is of importance for the formation of percolation paths on a large scale. ${ }^{67}$ The space charge suppression is not significant for wet $\mathrm{MgO} / \mathrm{LDPE}$ under high electric field. According to Yang et al., moisture destroys the charge suppression interface between filler and polymer matrix. ${ }^{68}$

However, the inherent moisture might also introduce ionic carriers, making the ionic conduction as a part of the total conduction. Also, the water content will also affect the electronic surface traps.

Moreover, insulation systems containing additives, byproducts, or something similar may be more sensitive to humidity than clean material ${ }^{69}$ because of ionic dissociation in the presence of moisture. ${ }^{70}$ Thus it is important to control the amount of absorbed moisture in polymeric insulation material as this governs the dynamics of the charge build-up and decay in the epoxy resin samples.

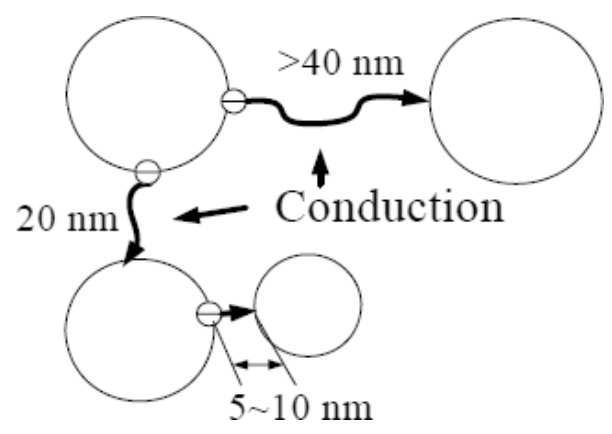

(a)

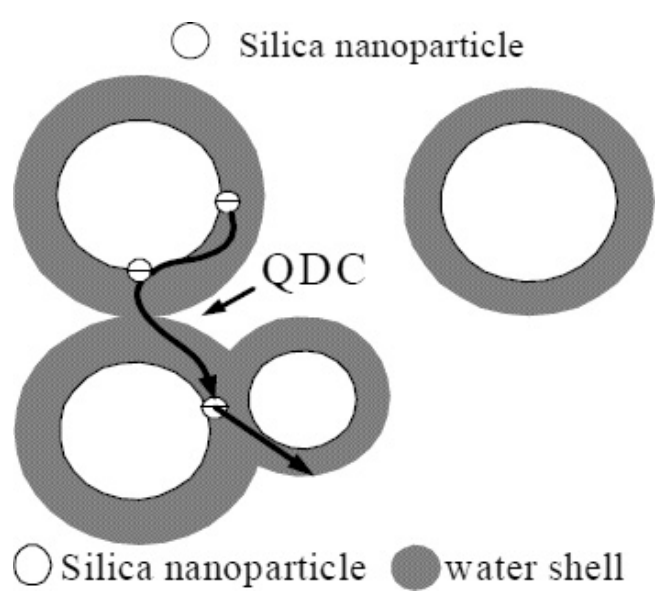

(b)

Fig. 8. Water shell model. ${ }^{66}$ (a) Without water, (b) with percolating water film.

\subsection{Insulation thickness}

One must be aware that the physics of space charge does not scale with sample thickness in a straightforward manner. This is known even from the simple case of unipolar space charge limited conduction. In a recent study Lv et al. ${ }^{71}$ investigated the dependence of space charge on sample thickness of pure and $\mathrm{SiO}_{2}$-filled LDPE. They interpret their observations, like the disappearance of hetero-charge for increased thickness, by enhanced electron-hole recombination, which depends furthermore on the trap density. This may explain the differences between the space charge behavior in unfilled and filled LDPE.

\subsection{Technical constrains of current technology}

Although PEA is currently mostly used for space charge measurement, there are still some problems that affect the accuracy of the method. Sound signal transfer is the key aspect in the measurement, where several factors will influence the process.

One factor is the contact between sample and the electrode; if the contact is loose, then signal will be very weak or disappeared, while if the contact is too tight, semi-con layer will be broken or distorted resulting in poor signal reflection 
or high noise, moreover, the contact problem will be more complex in high temperature measurement. Therefore, contact should carefully be controlled through the measurement.

Another problem is from the signal processing. Currently different systems use different algorithms, including the differences in deconvolution, filtering parameter, method to deal with the overshooting, etc., therefore, results from different labs or PEA systems are not easily compared. Moreover, the signal processing method will also influence the resolution of the measurement.

Moreover, the acoustic signal will attenuate in the polymeric sample significantly, and thus PEA method is so not good at measuring thick samples. When measuring thick flat samples, or cable section, a high pulsed voltage must be applied, which may generate some space charge itself.

These factors should be taken care of in measurement process and in comparing the results from different literatures or systems. Anyway, the PEA technology is still progressing and these problems will be gradually solved, and also IEC had released a standard to regulate the method.

\section{Influence of Bulk Material Properties}

Electric conduction and space charge behavior are properties of the system consisting of insulator and contacts. There are interior factors of the bulk material that influence space charge behavior. Among them one may differentiate between bulk properties of the matrix polymer, like microstructure (morphology) and chemical composition, and additives like anti-oxidants, cross-linking by-products and filler particles. Knowledge and understanding of how the space charge properties relate to these factors is of huge interest for the selection, design, and fabrication of an optimum material.

\subsection{Microstructure}

The microstructure of polymer materials is established during the processing and molding. Thus, not only the selection of a specific polymer material but also the choice of appropriate process parameter may improve the space charge behavior of final product. The following discussion indicates that it can be advantageous to use high annealing rates, nucleating agents, and random copolymers.

Space charges depend on the crystalline morphology of semi-crystalline polymers like PE, PP, ${ }^{3,72}$ etc., because of the intimate relation between space charge and (physical) carrier traps, whose origin from the physical defects such as cavities is formed by local arrangement of molecular chains. ${ }^{73}$ LDPE Samples with different degrees of crystallinity show quite different space charge behaviors, ${ }^{74,75}$ and the ones with higher crystallinity have more homo-charge accumulation, lower mobility, and higher trap depth. Montanari et al. ${ }^{3}$ found, by comparing XLPE, LDPE, and HDPE, that (i) the two latter have similar threshold field values but lower than XLPE, while (ii) the two former have less amount of space charge than HDPE. Also the branch length and molecular weight of the three PE types have a large influence on the space charge formation. ${ }^{76}$

Furthermore, when introducing nucleating agent (which could be sorbitol based, HDPE, or metal-locene catalyzed PE) to LDPE, ${ }^{77-79}$ more but smaller and less perfect spherulites appear, with more interfaces between crystalline and amorphous phases. This results in a higher and more homogeneously distributed conductivity, and thus less space charge. Similar results were reported for quenched polytetrafluoroethylene (PTFE), ${ }^{80}$ where the decrease of crystallinity and crystallite sizes attribute to the decrease of space charge by improving the carrier mobility. PPs with different chemical structures also behave differently in space charge distribution for their chemical sequence structure and crystalline microstructure. Compared with homo-PP, the regularity of sequence structure in block and random co-PP is broken with incorporation of other units (mostly ethylene units), which hold back the crystallization of propylene units, resulting in imperfect and fine crystalline morphology. The imperfect and fine crystalline morphology eventually contributes to the formation of considerable shallow traps, which is more remarkable at low annealing temperature. ${ }^{81}$

\subsection{Additives and cross-linking by-products}

Space charge depends also on additives and reaction byproducts, because of the intimate relation between space charge and chemical traps, whose origin is from additional chemical species. Additives mentioned here include nucleating agent, antioxidant, by-products (e.g., cumyl-alcohol, acetophenone, $\alpha$-methylstyrene, or water for silane-based grafting) caused by crosslink reaction, etc., but do not include inorganic nano- or micro-filler (see next subsection).

The effect of nucleating agent is obviously two-fold, as it can lead to physical and chemical traps. Dibenzylidene sorbitol (DBS) with/above a certain concentration (0.3\%) forms a network within PE blends, preventing the polymer to form big spherulites, smoothing the space charge distribution in both charging ${ }^{82}$ and discharging ${ }^{83}$ processes. By blending LDPE with $5 \mathrm{wt} . \%$ of poly (ethylene-co-vinyl alcohol, EVOH), space charge accumulation is decreased, since the blending leads to smaller spherulites and thus higher conductivity. According to the authors, also trapping of homocharge at interface of the EVOH domains may play a role. ${ }^{84}$

Oxidation enhances charge injection in LDPE. ${ }^{85}$ The addition of the antioxidant changes both space charge formation and the space charge decay markedly. It leads to hopping centers in the amorphous regions which enhances the conductivity, but leads to deep (i.e., chemical) traps on the crystallite surfaces, which can decrease the conductivity. The effect of oxidation thus depends on the crystallinity. ${ }^{86,87}$ Therefore one cannot say that antioxidants in general will reduce space charge. Some antioxidants enhance the heterocharge in $\mathrm{LDPE}^{73,88}$ as well as charge injection and/or charge 
transport, and the amount of space charge increases with the antioxidant content ${ }^{89}$; yet antioxidant is necessary in LDPE. These results show that the addition of antioxidants into the LDPE induces trap sites within the system.

Crosslinking by-products can also have large effects on space charge. Without degassing they influence the conductivity such that already their density gradient can induce space charge via a conductivity gradient. Even with degassing, some traces will remain and need to be taken into consideration, e.g., as traps. Nibbio argued that by-products act as a key carrier sources under low electric field, and antioxidants take it over under high electric field. ${ }^{90}$ Fukuyama et al. believe that the synergetic effect between the by-product and antioxidant is the cause of the hetero-charge profile observed in XLPE. ${ }^{91}$ A number of experiments have been designed for the clarification how the crosslinking byproducts affect the space charge formation and which byproduct is the dominant. ${ }^{69,88,92-94}$ For instance, Maeno et al. ${ }^{69,92-94}$ reported that cumyl-alcohol is responsible for homo-charge in LDPE and XLPE, acetophenone for heterocharge in XLPE, and $\alpha$-methylstyrene has no effect in LDPE but provides traps in XLPE. It is believed that space charge can be significantly reduced with a proper elimination of all the crosslinking by-products (de-gassing), water, and carbonyl groups.

\subsection{Filler}

The addition of fillers can lead to an improvement of polymer insulation material properties. ${ }^{95}$ Nanodielectrics ${ }^{96,97}$ became a fashionable topic over the years, and it is believed that in these materials charge injection may be suppressed. ${ }^{98-101}$

While huge amounts of both positive and negative packetlike charge injection was observed when investigating LDPE samples by PEA, this phenomenon was absent in nano-MgOfilled LDPE even at high field. ${ }^{102}$ Similar results were reported for $\mathrm{MgO}^{100}$ or $\mathrm{Al}_{2} \mathrm{O}_{3}{ }^{108}$ filled epoxy resins. Maezawa et al. $^{102}$ illustrated the charge injection suppression effect with nanoparticles via the schematic diagrams in his paper. Due to the relative permittivity (conductivity) ratio between polymer matrix and organic filler, the capacitive (resistive) potential distribution is distorted under an applied voltage. The potential distribution has been calculated and has the form of a well. Both electrons and holes are captured when they are near the filler particle. By considering the cross-sectional area where the potential is deeper than the threshold, one can estimate the injection distance from anode depending on the external electric field. It was found that when one applies a higher electric field, the injection distance from anode is shorter. Andritsch et al. ${ }^{100}$ gave another explanation: nanoparticles might provide electron-hole recombination centers (see Fig. 9). While electrons approach the particles between the chains, holes travel along the chains. Once the carriers reach a particle, they tunnel through the particle surface and recombine.

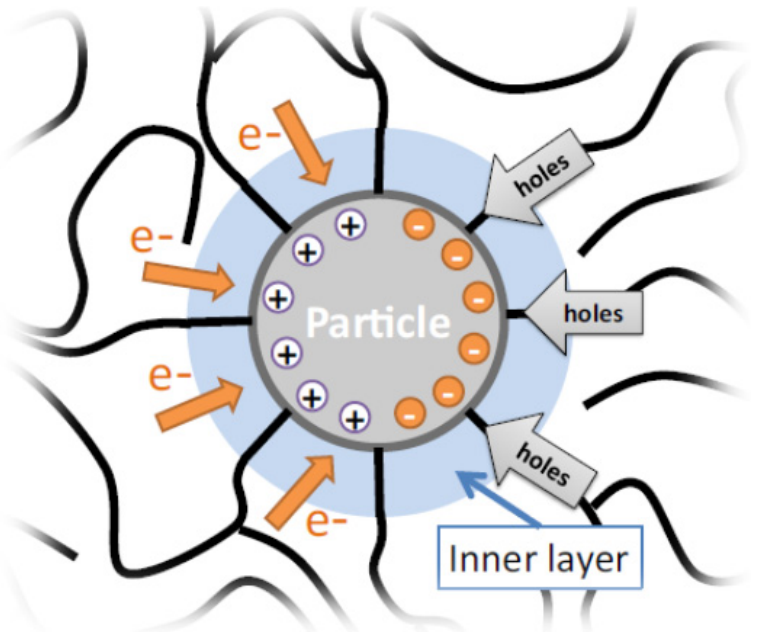

Fig. 9. The conduction of carriers around an inorganic filler particle with electron-hole recombination at the surface. ${ }^{100}$

\subsubsection{Amount of filler content}

Appropriate content of inorganic powder can distinctly reinforce the breakdown strength of polymer insulation, but the use of excessive powder shows the opposite effect. ${ }^{103}$ Chakraborty et al. came to the same conclusion for nano $\mathrm{Al}_{2} \mathrm{O}_{3}$-filled epoxy resin composites. An amount of $0.5 \mathrm{wt} . \%$ $\mathrm{Al}_{2} \mathrm{O}_{3}$ /epoxy resin showed the best suppression of space charge. However, the conclusions are not always consistent. ${ }^{8}$ When nano- $\mathrm{Al}_{2} \mathrm{O}_{3}$ concentration in epoxy resin is up to 15 wt. $\%$, charge injection has been enhanced. ${ }^{61}$ Table 2 lists some composites with (moderately) improved space charge behavior.

\subsubsection{Filler type}

The inorganic fillers are usually insulating metal oxides or semiconductor oxide particles. The specific filler type also has a significant influence on space charge accumulation. We consider $\mathrm{SiO}_{2}$ and $\mathrm{Al}_{2} \mathrm{O}_{3}$ in epoxy resin a first example. ${ }^{114,115}$

Table 2. Composite insulations reported with their optimal content.

\begin{tabular}{|c|c|c|c|}
\hline Matrix & Filler type & Particle size & Optimal content \\
\hline $\mathrm{LDPE}^{98,102,104}$ & $\mathrm{MgO}$ & Nano & $>1 \mathrm{wt} . \%$ \\
\hline $\mathrm{LDPE}^{105}$ & $\mathrm{MgO}$ & Micro & 5 wt. $\%$ \\
\hline $\mathrm{LDPE}^{106}$ & $\mathrm{SiO}_{2}$ & $7 \mathrm{~nm}, 12 \mathrm{~nm}, 16 \mathrm{~nm}$ & 2 wt. $\%$ \\
\hline $\mathrm{LDPE}^{99}$ & $\mathrm{MgO}$ & Nano & $1 \mathrm{wt} . \%$ \\
\hline $\mathrm{LDPE}^{107}$ & O-MMT & Nano & $0.5 \%$ \\
\hline $\mathrm{LDPE}^{108}$ & Zeolite & $100 \mathrm{~nm}$ & 3 wt. $\%$ \\
\hline $\mathrm{PE}^{109}$ & MMT & Not mentioned & $0.5 \%$ \\
\hline $\mathrm{XLPE}^{110}$ & $\mathrm{MgO}$ & Nano & 0.5 wt. $\%$ \\
\hline $\mathrm{XLPE}^{111}$ & $\mathrm{ZnO}$ & $20 \mathrm{~nm}, 200 \mathrm{~nm}$ & 3 wt. $\%$ \\
\hline $\mathrm{PP}^{112}$ & Natural clay & Nano & 2 wt. $\%$ \\
\hline $\mathrm{PP}^{112}$ & Synthetize clay & Nano & $2-4$ wt. $\%$ \\
\hline Epoxy $^{8}$ & $\mathrm{Al}_{2} \mathrm{O}_{3}$ & $90-120 \mathrm{~nm}$ & $0.5 \%$ \\
\hline Polyamideimide $^{113}$ & $\mathrm{MgO}$ & $40-50 \mathrm{~nm}$ & $10 \mathrm{wt} . \%$ \\
\hline Polyamideimide $^{113}$ & $\mathrm{Al}_{2} \mathrm{O}_{3}$ & $50 \mathrm{~nm}$ & $7.5 \%$ \\
\hline
\end{tabular}


With the same filler concentrations and under the same electric condition and history, homo-charges form in epoxy resin $/ \mathrm{Al}_{2} \mathrm{O}_{3}$, whereas hetero-charges predominate in epoxy resin $/ \mathrm{SiO}_{2}$. This might be caused by an enhancement of ionization in epoxy resin/ $\mathrm{SiO}_{2}$. A second example is given by $\mathrm{Xu}$ et al. ${ }^{116}$ once charge injection has occurred in the sample, the micro- $\mathrm{SiO}_{2}$ filled epoxy has higher conductivity and thus lower space charge than epoxy with micro-BN.

\subsubsection{Filler particle size}

Polymeric composites with the same filler type but different size may also show different charge behavior, which is especially pronounced when the filler content is low. With the same relative low mass fraction of a filler, packet-like space charge moves faster in nano-MgO/LDPE than that in micro$\mathrm{MgO} / \mathrm{LDPE} .{ }^{105} \mathrm{Xu}$ et al. also studied the effect of addition of micro/nano- $\mathrm{SiO}_{2}$ to an epoxy matrix. The threshold field of low content $(5 \%)$ nano- $\mathrm{SiO}_{2}$ composite is higher than for the micro-fillers. ${ }^{116}$ Furthermore, the presence of nano-filler decreases the space charge decay rate, ${ }^{117}$ and the smaller the size, the stronger the decrease. ${ }^{106}$ Fablani et al. concluded that nano- $\mathrm{SiO}_{2}$ filled epoxy resin shows considerably decrease in conduction current and space charge density. ${ }^{118}$ Taking thermal characteristics into consideration, epoxy resin composites containing both micro- and nano-fillers should be tailored to obtain good comprehensive performances.

\subsubsection{Filler modification}

Silane coupling agent has been widely applied to improve the compatibility of organic-inorganic compound material. Modification of the filler can improve the space charge behavior of insulation. Compared to unmodified fillers, modified $\mathrm{Al}_{2} \mathrm{O}_{3}$ by silane coupling agent improved both the breakdown strength and solidity of the epoxy resin composites, the former essentially by optimization of the space charge distribution. ${ }^{8}$ Silane treated nano-ZnO (or MMT) also improves the breakdown strength. ${ }^{109,111}$ Nanofilled materials

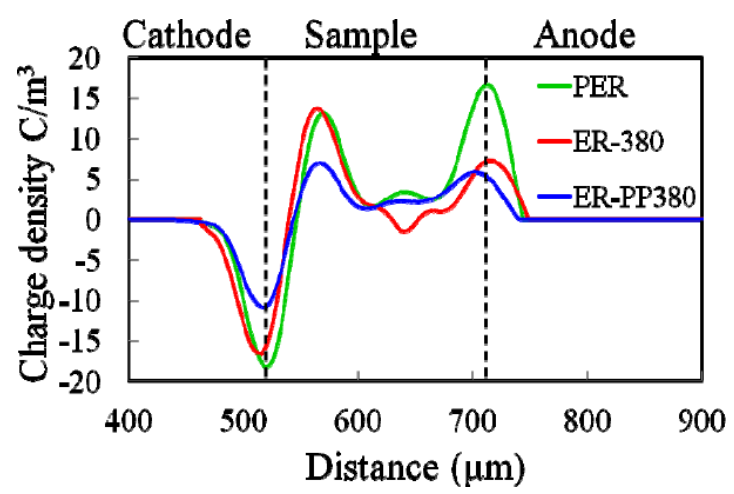

Fig. 10. Space charge distribution of the PER (pure epoxy resin), ER-380 (ER filled with 3 wt.\% of as-reserved $\mathrm{SiO}_{2}$ ) and ER-PP380 (ER filled with 3 wt.\% of plasma-treated $\mathrm{SiO}_{2}$ ). ${ }^{119}$ prevent space charge formation by suppressing the carrier flow, e.g., for nano-ZnO in XLPE. Likewise, in order to improve the adhesion between $\mathrm{SiO}_{2}$-particles and epoxy resin, the nanoparticles were coated with poly (ethylene oxide)-like films after modification in a plasma polymerizer. Figure 10 shows that the space charge distribution of pure epoxy, epoxy resin filled with plasma-treated and untreated $\mathrm{SiO}_{2}$. It turned out that the benefit of plasma-treated nanocomposite with respect to the suppression of space charge comes into effect at a loading above $3 \mathrm{wt} . \%^{119,120}$ Maleic anhydride grafted polyethylene (PEMA) can also induce interfacial traps in LDPE/OMMT (organo-montmorillonite). ${ }^{107}$

\section{Summary and Conclusion}

This paper reviewed measurements of space charge behavior with the PEA technique, the results of which are affected by multiple testing factors and samples properties. Moreover, as the DC and low-frequency electrical behavior of insulation material is generally not robust, the space charge behavior is not too. It is particularly not a stable bulk material property, but depends strongly on many factors. This makes an accurate prediction of field distributions difficult, and should thus be mitigated. Although well known since a long time, this issue can still be a problem for HVDC insulation.

Several factors in PEA measurement were summarized. Space charge usually forms at a threshold field, and charge density profiles can be measured up to breakdown field; in between secondary dynamic instabilities, like charge packet waves, may occur. The temperature and temperature gradients must be taken into consideration. An insulator electrode system should at least be characterized by the $E_{\mathrm{th}}$ ( $T$ ) curve in the $T-E$ plane, i.e., the threshold field as a function of temperature. Because higher temperature implies higher mobility, one expects $d E_{\mathrm{th}}(T) / d T<0$. Under certain conditions, however, higher mobility may also cause increased hetero-charge accumulation. Also humidity or water content is a parameter which must be under control, since it can accelerate charge injection and accumulation.

Space charge behavior is of course significantly affected by the tested material itself. The effect of the morphology, crystallinity, and crystal sizes of semi-crystalline polymer insulation seems to be often understandable from the picture that the "inter-phase", i.e., the crystal-amorphous interface regions, are responsible for conduction. Microstructures achieved under high annealing rates, with the presence of nucleating agent and by choosing random copolymer might be advantageous. Nevertheless, also this statement must be qualified and be analyzed on a case-by case basis because of the strong dependence on other factors, like traps that may form in the interfaces in the case of strong oxidation, and reducing by this mobility. In general, additives can have several effects. By acting as deep (chemical) traps homocharge may be increased and hetero-charge decreased if conduction is electronic. On the other hand, by acting as a 
source for ions, hetero-charge may be increased. Again, a case-by case investigation is necessary. In comparison to filler-free insulations, polymeric composites with fillers may be advantageous due to a suppression of space charge. Nanofillers perform better than micro-fillers. Appropriately modified-fillers can even improve the situation.

There had been so many great efforts put into the space charge area, making the PEA method more accurate and pushing forward our understanding of bulk insulation mechanism. Although a number of commercial PEA-based space charge measurement systems are available, this technique is still under improvement, and an indubitably accurate revelation of space charge behavior is still a challenge. Furthermore, research on ageing and breakdown mechanisms resulting from space charge is far from conclusive.

On one hand, from the measurement point of view, it is important to further investigate how the factors are impacting the results, so as to make the results more accurate and comparable, by regulating standardized testing procedure and also more optimal conditioning parameters. On the other hand, more effects and results were needed to understand the conduction and breakdown mechanisms with regard to space charge, in order to instruct the insulation design and material selection or development for HVDC applications.

\section{References}

${ }^{1}$ T. Mizutani, E. Nakane, K. Kaneko, M. Ishioka and H. Takino, Space charge and charge transport in polypropylene, 2005 12th Int. Symp. Electrets, 2005. ISE-12 (2005), pp. 475-478.

${ }^{2}$ M. Abou-Dakka, Evolution of space charges and conductivity with DC aging of polyethylene-synthetic and natural clay composites, J. Nanomater. 2012, 8 (2012).

${ }^{3}$ G. C. Montanari et al., Space-charge trapping and conduction in LDPE, HDPE and XLPE, J. Phys. D: Appl. Phys. 34, 2902 (2001).

${ }^{4}$ A. S. Alghamdi, D. H. Mills and P. L. Lewin, Influence of ageing on space charge and electroluminescence of epoxy resin, 2010 10th IEEE Int. Conf. Solid Dielectrics (ICSD) (2010), pp. 1-4.

${ }^{5}$ N. Xin, X. Zhen, P. Zongren, Z. Shilling and C. Shaoqing, Effect of UV ageing on space charge characteristics of epoxy resin and its nanocomposites, 2013 IEEE Int. Conf. Solid Dielectrics (ICSD) (2013), pp. 784-787.

${ }^{6} \mathrm{G}$. C. Montanari, Relation between space charge and polymeric insulation ageing: Cause and effect, IEE Proc. - Sci. Meas. Technol. 150, 53 (2003).

${ }^{7}$ S. Das and N. Gupta, Charge trapping and transport phenomenon in aged and unaged epoxy resin and polyethylene, Int. Trans. Electr. Energy Syst. 25, 948 (2014).

${ }^{8}$ H. Chakraborty, A. Sinha, S. Chabri and N. Bhowmik, Effect of space charge density and high voltage breakdown of surface modified $\mathrm{Al}_{2} \mathrm{O}_{3}$ reinforced epoxy composites, Trans. Electr. Electron. Mater. 14, 121 (2013).

${ }^{9}$ O. Gallot-Lavallée, G. Teyssèdre, C. Laurent and S. Rowe, Space charge behaviour in an epoxy resin: The influence of fillers, temperature and electrode material, J. Phys. D: Appl. Phys. 38, 2017 (2005).
${ }^{10} \mathrm{M}$. Fujii et al., Dielectric properties and space charge formation in polypropylene film up to AC breakdown, in Proc. 7th Int. Conf. Properties and Applications of Dielectric Materials, 2003, Vol. 582 (2003), pp. 587-590.

${ }^{11}$ M. Fukuma, M. Nagao and M. Kosaki, Measurements of breakdown pressure wave and cathode and anode electric field up to electrical breakdown in PP film, IEEE 1997 Annual Report, Conf. Electrical Insulation and Dielectric Phenomena, 1997, Vol. 181, (1997), pp. 181-185.

${ }^{12} \mathrm{G}$. C. Montanari, Bringing an insulation to failure: The role of space charge, IEEE Trans. Dielectr. Electr. Insulat. 18, 339 (2011).

${ }^{13} \mathrm{~W}$. Li et al., Physicochemical origin of space charge dynamics for aged XLPE cable insulation, IEEE Trans. Dielectr. Electr. Insulat. 21, 809 (2014).

${ }^{14}$ G. Mazzanti, G. Montanari and J. A. Alison, Space-charge based method for the estimation of apparent mobility and trap depth as marksers for degradation, IEEE Trans. Dielectr. Electr. Insulat. 10, 187 (2003).

${ }^{15}$ O. Gallot-Lavallee, G. Teyssedre, C. Laurent and S. Rowe, Space charge and orientational polarization within epoxy as probed by the pulsed electro-acoustic technique, Electrical Insulation and Dielectric Phenomena, 2003. Annual Report. Conf. (2003), pp. 249-252.

${ }^{16} \mathrm{M}$. Natsui et al., Possibility of non-destructive detection of electrochemical migration in epoxy resin by the pulsed electroacoustic method, Electrical Insulation and Dielectric Phenomena, 2009. CEIDP'09. IEEE Conf. (IEEE, 2009), pp. 104-107.

${ }^{17} \mathrm{G}$. Chen, Space charge measurement as a diagnostic tool to monitor ageing in polymeric materials, Trans. Electr. Electron. Mater. 7, 235 (2006).

${ }^{18}$ T. Maeno, T. Futami, H. Kushibe, T. Takada and C. M. Cooke, Measurement of spatial charge distribution in thick dielectrics using the pulsed electroacoustic method, IEEE Trans. Electr. Insulat. 23, 433 (1988).

${ }^{19}$ G. C. Montanari and P. H. F. Morshuis, Space charge phenomenology in polymeric insulating materials, IEEE Trans. Dielectr. Electr. Insulat. 12, 754 (2005).

${ }^{20} \mathrm{~K}$. Fukunaga, Progress and prospects in PEA space charge measurement techniques, IEEE Electr. Insulat. Mag. 24, 26 (2008).

${ }^{21}$ R. Fleming, Space charge in polymers, particularly polyethylene, Braz. J. Phys. 29, 280 (1999).

${ }^{22}$ E. Nakane, et al., Effects of electrodes on space charge in polypropylene, 2005 Annual Report Conf. Electrical Insulation and Dielectric Phenomena, 2005. CEIDP '05 (2005), pp. 653-656.

${ }^{23}$ G. Chen, T. Y. G. Tay, A. E. Davies, Y. Tanaka and T. Takada, Electrodes and charge injection in low-density polyethylene using the pulsed electroacoustic technique, IEEE Trans. Dielectr. Electr. Insulat. 8, 867 (2001).

${ }^{24} \mathrm{M}$. Fukuma and T. Itoga, Space charge signal in line-plate electrode system under DC field on PEA method, Annual Report - Conf. Electrical Insulation and Dielectric Phenomena, 2007. CEIDP 2007 (2007), pp. 639-642.

${ }^{25} \mathrm{~K}$. Bambery and R. Fleming, Space charge accumulation in 2 power cable grades of XLPE, IEEE Trans. Dielectr. Electr. Insulat. 5, 103 (1998).

${ }^{26} \mathrm{M}$. Fu, G. Chen and J. Fothergill, "Mirror Image" space charge distribution in XLPE power cable under opposite stressing voltage polarity, 14th Int. Symp. HV Eng., 2005, Proceedings (2005), Paper H-03, 5 pp. 
${ }^{27}$ T. Mizutani, E. Nakane, K. Kaneko and M. Ishioka, Space charge dynamics in polypropylene, 2004 Annual Report Conf. Electrical Insulation and Dielectric Phenomena, 2004. CEIDP '04 (2004), pp. 33-36.

${ }^{28} \mathrm{~K}$. Matsui et al., Space charge behavior in low density polyethylene at pre-breakdown, IEEE Trans. Dielectr. Electri. Insulat. 12, 406 (2005).

${ }^{29}$ L. A. Dissado, C. Laurent, G. C. Montanari and P. H. F. Morshuis, Demonstrating a threshold for trapped space charge accumulation in solid dielectrics under DC field, IEEE Trans. Dielectr. Electr. Insulat. 12, 612 (2005).

${ }^{30} \mathrm{~S}$. Das and N. Gupta, Space charge mapping and conduction current measurements in epoxy and polyethylene, 2012 Annual Report Conf. Electrical Insulation and Dielectric Phenomena (CEIDP) (IEEE, 2012), pp. 645-648.

${ }^{31} \mathrm{~S}$. Das and N. Gupta, Effect of thermal and humidity ageing on space charge accumulation in epoxy resin, 2013 IEEE Int. Conf. Solid Dielectrics (ICSD) (IEEE, 2013), pp. 456-459.

${ }^{32}$ X. Ning, Z. Xiang, P. Liu, H. Feng and Z. Peng, Space charge behavior of epoxy resin at high temperature, 2013 IEEE Conf. Electrical Insulation and Dielectric Phenomena (CEIDP) (IEEE, 2013), pp. 222-225.

${ }^{33}$ C. Zou, J. Fothergill, S. Zhang and X. Zhou, DC conduction mechanisms in epoxy nanocomposites under the humid environment, 2010 10th IEEE Int. Conf. Solid Dielectrics (ICSD) (IEEE, 2012), pp. 1-4.

${ }^{34} \mathrm{~S}$. Das and N. Gupta, Space charge accumulation in epoxy resin and polyethylene, Properties and Applications of Dielectric Materials (ICPADM), 2012 IEEE 10th Int. Conf. (IEEE, 2012), pp. 1-4.

${ }^{35}$ L. Peng, X., Zhen, N. Xin, F. Hua and P. Zongren, Effect of electrode material on space charge behavior in epoxy resin, 2013 IEEE Conf. Electrical Insulation and Dielectric Phenomena (CEIDP) (2013), pp. 230-233.

${ }^{36} \mathrm{G}$. Teyssedre, C. Laurent and G. Montanari, From LDPE to XLPE: Investigating the change of electrical properties. Part II: Electroluminescence, IEEE Trans. Dielectr. Electr. Insulat. 12, 447 (2005).

${ }^{37}$ F. Magraner et al., Space charge measurements on different epoxy resin-alumina nanocomposites, 2010 10th IEEE Int. Conf. Solid Dielectrics (ICSD) (IEEE, 2010), pp. 1-4.

${ }^{38}$ Y. Liu and M. M. A. Salama, Space charge distribution measurements in polymers under needle-plane electrode configurations by pulsed electro-acoustic method, Electrical Insulation and Dielectric Phenomena, 1995. Annual Report, Conf. (1995), pp. 294-297.

${ }^{39}$ T. Hori, K. Kaneko, T. Mizutani and M. Ishioka, Effects of electrodes on space charge in low-density polyethylene, in Proc. 7th Int. Conf. Properties and Applications of Dielectric Materials, 2003, Vol. 853 (2003), pp. 855-858.

${ }^{40}$ K. Kaneko, E. Nakane, Y. Suzuoki and T. Mizutani, Effects of electrode on space charge properties of polyimide films, 8th Int. Conf. Properties and applications of Dielectric Materials, 2006 (2006), pp. 73-76.

${ }^{41} \mathrm{~K}$. Kaneko et al., Effects of electrode material on injection and space charge formation in polyimide, IEEE Int. Conf. Solid Dielectrics, 2007. ICSD '07 (2007), pp. 518-521.

${ }^{42}$ D. Xiaobing, Y. Yi, Z. Li and L. Xuguang, Space charge in lowdensity polyethylene/micro-SiO2 composite and low-density polyethylene/nano-SiOx composite with different metal electrode pairs, IEEE Int. Conf. Solid Dielectrics, 2007. ICSD '07 (2007), pp. 377-380.

${ }^{43} \mathrm{X}$. Chun et al., Space charge injection in LLDPE from electrode influenced by the interface state of material, IEEE 9th Int. Conf. Properties and Applications of Dielectric Materials, 2009. ICPADM 2009. (2009), pp. 899-902.

${ }^{44} \mathrm{~W}$. Peng, A practical on-line electro-optic measurement equipment for the measurement of electric field and space charge distribution in an electrode geometry with nonuniform electric field distribution, IEEE Int. Conf. Plasma Science - Abstracts, 2009. ICOPS 2009, (San Diego, CA, 2009), pp. 1-1.

${ }^{45}$ Y. Murakami, T. Sugiyama, R. Funo, M. Fukuma and M. Nagao, Influence of interfacial condition between film and lower electrode on space charge measurement, 2013 IEEE Conf. Electrical Insulation and Dielectric Phenomena (CEIDP) (2013), pp. 1062-1065.

${ }^{46} \mathrm{R}$. Fleming, M. Henriksen and J. Holboll, The influence of electrodes and conditioning on space charge accumulation in XLPE, IEEE Trans. Dielectr. Electr. Insulat. 7, 561 (2000).

${ }^{47}$ Y. Ho et al., Effect on semicon screen on the space charge dynamic in XLPE and polyolefin insulation under DC and $50 \mathrm{~Hz}$ AC electric stress conditions, IEEE Trans. Dielectr. Electr. Insulat. 10, 393 (2003).

${ }^{48}$ T. Muronaka, Y. Tanaka, T. Takada, S. Maruyama and H. Mutou, Measurement of space charge distribution in XLPE cable using PEA system with flat electrode, IEEE 1996 Annual Report Conf. Electrical Insulation and Dielectric Phenomena, 1996, Vol. 261 (1996), pp. 266-269.

${ }^{49}$ H. Zheng et al., Feasibility of using a flat bottom electrode for PEA space charge measurement on mini-cables under high temperatures, El. Ins. and Diel. Phenomena (CEIDP) 2013 (IEEE, 2013) pp. 1109-1112.

${ }^{50}$ Y. Zhang, F. Zheng, Z. An and X. Zhang, Research on space charge in insulating and functional dielectrics at Tongji University, IEEE Electr. Insulat. Mag. 38, 14 (2012).

${ }^{51}$ D. Fabiani et al., Polymeric HVDC cable design and space charge accumulation: Part 1-3, IEEE Electr. Insulat. Mag. 23(6), 11 (2007); 24(1), 14 (2008); 24(2), 5 (2008).

${ }^{52}$ E. Nakane, K. Kaneko, T. Mitzutani, H. Takino and M. Ishioka, Comparison of space charge behavior between polypropylene and polyethylene, in Proc. 2005 Int. Symp. Electrical Insulating Materials, 2005. (ISEIM 2005), Vol. 563 (2005), pp. 569-571.

${ }^{53} \mathrm{Z}$. Feihu et al., Use of dynamic space charge measurements to differentiate charge injection and ionic dissociation in polypropylene, 13th Int. Symp. Electrets, 2008. ISE-13 (2008), p. B0702.

${ }^{54}$ Y. Zheng, Q. Wang, Y. Yin and X. Li, Temperature effect on space charge dynamics in LDPE/MgO nanocomposite under DC stress, 2010 10th IEEE Int. Conf. Solid Dielectrics (ICSD) (IEEE, 2010), pp. 1-4.

${ }^{55}$ K. Fukunaga, T. Maeno and V. Griseri, Space charge observation of a filler free epoxy resin, 2000 Annual Report Conf. Electrical Insulation and Dielectric Phenomena, Vol. 121 (2000), pp. 125127.

${ }^{56} \mathrm{~S}$. Chen, Z. Peng and X. Wang, Effects of glass transition temperature on space charge in epoxy resin, Trans. China Electrotech. Soc. 26, 227 (2011).

${ }^{57} \mathrm{Q}$. Wang and S. Chen, Investigation of the effects of temperature on space charge distribution of epoxy resin, Sichuan Electr. Power Technol. 35, 65 (2013). 
${ }^{58}$ L. Boudou, V. Griseri, J. Guastavino and L. Dissado, Effect of temperature on space charge formation in low density polyethylene: Role of antioxidant, IEEE Int. Conf. Solid Dielectrics ICSD 2004 (IEEE, 2004), pp. 252-255.

${ }^{59}$ B. Alijagic-Jonuz, P. H. F. Morshuis and J. J. Smit, Effect of temperature and humidity on space charge quantities, $2002 \mathrm{An}$ nual Report Conf. Electrical Insulation and Dielectric Phenomena (2002), pp. 903-905.

${ }^{60} \mathrm{~T}$. Iizuka, H. Takai, K. Fukunaga and T. Maeno, Measurement of space charge distribution in epoxy resin after water absorption treatment, IEEE 1997 Annual Report, Conf. Electrical Insulation and Dielectric Phenomena, 1997, Vol. 41 (1997), pp. 41-44.

${ }^{61}$ A. Hajiyiannis, G. Chen, C. Zhang and G. Stevens, Space charge formation in epoxy resin including various nanofillers, Annual Report Conf. Electrical Insulation and Dielectric Phenomena, 2008. CEIDP 2008 (2008), pp. 714-717.

${ }^{62}$ H. Tanaka, Y. Ohki, K. Fukunaga, T. Maeno and K. Okamoto, Influence of water absorption on charge formation in printed circuit board insulations, in Proc. 2005 Int. Symp. Electrical Insulating Materials, 2005. (ISEIM 2005) Vol. 51 (2005), pp. 53-56.

${ }^{63} \mathrm{~A}$. Aragoneses et al., Effect of humidity in charge formation and transport in LDPE, J. Electrostat. 71, 611 (2013).

${ }^{64}$ Y. Echigo et al., Effects of humidity and temperature on space charge distribution profiles in printed circuit board insulations, IEEE Int. Conf. Solid Dielectrics, 2007. ICSD '07 (2007), pp. 458-461.

${ }^{65}$ G. C. Montanari and F. Palmieri, The effect of humidity on space charge accumulation in XLPE, Annual Report Conf. Electrical Insulation and Dielectric Phenomena, 2003 (2003), pp. 205-208.

${ }^{66} \mathrm{C}$. Zou, M. Fu, J. C. Fothergill and S. W. Rowe, The influence of water on dielectric behavior of silica-filled epoxy nano-composites and percolation phenomenon, Annual Report - Conf. Electrical Insulation and Dielectric Phenomena, 2007. CEIDP 2007 (2007), pp. 372-375.

${ }^{67}$ D. Fabiani, G. C. Montanari and L. Testa, Effect of aspect ratio and water contamination on the electric properties of nanostructured insulating materials, IEEE Trans. Dielectr. Electr. Insulat. 17, 221 (2010).

${ }^{68}$ J. M. Yang, X. Wang, C. Zheng, H. Zhao and Q. Q. Lei, Influence of moisture absorption on space charge property of $\mathrm{MgO}$ / LDPE nanocomposite, 2013 IEEE Conf. Electrical Insulation and Dielectric Phenomena (CEIDP) (2013), pp. 719-721.

${ }^{69}$ Y. Maeno et al., Effects of crosslinking byproducts on space charge formation in crosslinked polyethylene, IEEE Trans. Dielectr. Electr. Insulat. 12, 90 (2005).

${ }^{70}$ T. A. Ve, F. Mauseth and E. Ildstad, Effect of water content on the conductivity of XLPE insulation, 2012 Annual Report Conf. Electrical Insulation and Dielectric Phenomena (CEIDP) (2012), pp. 649-653.

${ }^{71} \mathrm{Z}$. Lv et al., Dependence of charge accumulation on sample thickness in Nano-SiO2 doped LDPE, IEEE Trans. Dielectr. Electr. Insulat. 20, 337 (2013).

${ }^{72}$ R. Nath and M. M. Perlman, Effect of crystallinity on charge storage in polypropylene and polyethylene, IEEE Trans. Electr. Insulat. 24, 409 (1989).

${ }^{73}$ T. Mizutani, Effects of additives and morphology on space charge in LDPE, in Proc. 2001 Int. Symp. Electrical Insulating Materials, 2001. (ISEIM 2001) (2001), pp. 487-492.
${ }^{74}$ Z. Yuanxiang et al., Morphology effects on space charge characteristics of low density polyethylene, Jpn. J. Appl. Phys. 50, 017101 (2011).

${ }^{75}$ Y.-X. Zhou et al., Effects of morphology on movement of space charge packet in polyethylene, High Voltage Eng. 11, 026 (2008).

${ }^{76}$ X. Wang, N. Yoshimura, K. Murata, Y. Tanaka and T. Takada, Space-charge characteristics in polyethylene, J. Appl. phys. 84, 1546 (1998).

${ }^{77}$ X. Li, Y. Cao, Q. Du, Y. Yin and D. Tu, Charge distribution and crystalline structure in polyethylene nucleated with sorbitol, $J$. Appl. Polymer Sci. 82, 611 (2001).

${ }^{78}$ Y. Lin, W. Du, D. Tu, W. Zhong and Q. Du, Space charge distribution and crystalline structure in low density polyethylene (LDPE) blended with high density polyethylene (HDPE), Polymer Int. 54, 465 (2005).

${ }^{79}$ X. Wang, C. Wu, D. Tu, C. Lei and Q. Du, Space charge distribution and crystalline structure in low-density polyethylene modified by metallocene catalyzed polyethylene, 8th Int. Conf. Properties and Applications of Dielectric Materials, 2006 (2006), pp. 139-142.

${ }^{80} \mathrm{C}$. Lei et al., Space charge distribution and crystalline structure in quenched polytetrafluoroethylene, Eur. Polym. J. 43, 4523 (2007).

${ }^{81}$ X. Li, Q. Du, J. Kang and D. Tu, Influence of microstructure on space charges of polypropylene, J. Polym. Sci. B Polym. Phys. 40, 365 (2002).

${ }^{82}$ G. Gherbaz and A. S. Vaughan, Polymer blend and nucleating agent: On structural evolution and space charge on polyethylene (PE) blends and Dibenzylidene Sorbitol, IEEE Int. Conf. Solid Dielectrics, 2007. ICSD '07 (2007), pp. 526-529.

${ }^{83}$ G. Gherbaz, G. Chen and A. S. Vaughan, Polyethylene/Dibenzylidene Sorbitol: Effect of composition on space charge of polymeric insulation systems, Annual Report Conf. Electrical Insulation and Dielectric Phenomena, 2008. CEIDP 2008 (2008), pp. 161-164.

${ }^{84}$ W. Du, W. Zhong, Y. Lin, L. Shen and Q. Du, Space charge distribution and crystalline structure in polyethylene blended with EVOH, Eur. Polym. J. 40, 1987 (2004).

${ }^{85}$ T. Mizutani, Y. Suzuoki, H. Kon and N. Yoshifuji, Effects of oxidation and antioxidants on space charge in polyethylene, Annual Report, Conf. Electrical Insulation and Dielectric Phenomena, 1995 (1995), pp. 89-92.

${ }^{86}$ Y. Tanaka et al., Effect of additives on morphology and space charge accumulation in low density polyethylene, IEEE Trans. Dielectr. Electr. Insulat. 10, 148 (2003).

${ }^{87}$ T. Mizutani, T. Tsukahara and M. Ieda, The effect of oxidation on the electrical conduction of polyethylene, J. Phys. D Appl. Phys. 13, 1673 (1980).

${ }^{88}$ T. Mizutani, Space charge measurement techniques and space charge in polyethylene, IEEE Trans. Dielectr. Electr. Insulat. 1, 923 (1994).

${ }^{89}$ T. Mizutani, K. Shinmura, Y. Taniguchi, K. Kaneko and M. Ishioka, Effect of anti-oxidants on space charge in lowdensity polyethylene, Proc. 2001 IEEE 7th Int. Conf. Solid Dielectrics, 2001. ICSD '01 (2001), pp. 228-231.

${ }^{90}$ N. Nibbio, T. Uozumi, N. Yasuda and T. Fukui, The effects of additives on space charge in XLPE insulation-crosslinking reagent and antioxidant, Conf. Record of the 1994 IEEE Int. Symp. Electrical Insulation, 1994 (1994), pp. 559-562. 
${ }^{91}$ T. Fukuyama, T. Nakui, Y. Sekii and T. Maeno, The influence of additives on the space charge formation and charge profiles in XLPE, Proc. 6th Int. Conf. Properties and Applications of Dielectric Materials, 2000, Vol. 51 (2001), pp. 51-54.

${ }^{92}$ Y. L. Chong, G. Chen and Y. F. F. Ho, The effect of degassing on morphology and space charge, in Proc. 2004 IEEE Int. Conf. Solid Dielectrics, 2004. ICSD 2004, Vol. 161 (2004), pp. 162-165.

${ }^{93} \mathrm{~N}$. Hussin and G. Chen, The effect of acetophenone and alphamethylstyrene on the space charge properties of low density polyethylene, Annual Report Conf. Electrical Insulation and Dielectric Phenomena, 2008. CEIDP 2008 (2008), pp. 702705.

${ }^{94}$ N. Hussin and G. Chen, Analysis of space charge formation in LDPE in the presence of crosslinking byproducts, IEEE Trans. Dielectr. Electr. Insulat. 19, 126 (2012).

${ }^{95}$ D. Zhang, H. Zhang, Z. Zhang and Y. Chen, Industry applications of nanotechnology in high performance insulation composites, Sci. Sin. Chim. 43, 725 (2013).

${ }^{96}$ T. Tanaka, Nanodielectics: How does the presence of interfaces influence behaviour?, 2011 Int. Conf. Power and Energy Systems (ICPS) (IEEE, 2011), pp. 1-4.

${ }^{97}$ L. Shengtao, Z. Lisheng, L. Jianying and G. Chen, A brief history and research progress on solid engineering dielectrics in China, IEEE Electr. Insulat. Mag. 26, 14-21 (2010).

${ }^{98} \mathrm{~J}$. Taima et al., Observation of space charge formation in LDPE/ $\mathrm{MgO}$ nano-composite under DC stress at high temperature, 2006 IEEE Conf. Electrical Insulation and Dielectric Phenomena (IEEE, 2006), pp. 302-305.

${ }^{99} \mathrm{~J}$. Yoshida et al., Space charge accumulation and breakdown in LDPE and LDPE/MgO nano-composite under high DC stress at various temperatures, IEEE Conf. Electrical Insulation and Dielectric Phenomena, 2009. CEIDP '09 (2009), pp. 150-153.

${ }^{100}$ T. Andritsch, R. Kochetov, B. Lennon, P. H. F. Morshuis and J. J. Smit, Space charge behavior of $\mathrm{MgO}$ filled epoxy nanocomposites at different temperatures and electric field strengths, Electrical Insulation Conf. (EIC), 2011 (2011), pp. 136-140.

${ }^{101}$ D. Fabiani et al., Space charge dynamics in nanostructured epoxy resin, Annual Report Conf. Electrical Insulation and Dielectric Phenomena, 2008. CEIDP 2008 (2008), pp. 710-713.

${ }^{102}$ T. Maezawa, J. Taima, Y. Hayase, Y. Tanaka and T. Takada, Space charge formation in LDPE/MgO nano-composite under high electric field at high temperature, Annual Report Conf. Electrical Insulation and Dielectric Phenomena, 2007. CEIDP 2007 (IEEE, 2007), pp. 271-274.

${ }^{103}$ Z. Feihu, Z. Yewen, X. Junfeng and X. Chun, Effect of inorganic oxide nano powder on space charge breakdown behavior in electron beam irradiated nano/PMMA composites, 8th Int. Conf. Properties and applications of Dielectric Materials, 2006 (2006), pp. 331-334.

${ }^{104}$ Y. Murakami et al., DC conduction and electrical breakdown of $\mathrm{MgO} / \mathrm{LDPE}$ nanocomposite, IEEE Trans. Dielectr. Electr. Insulat. 15, 33 (2008).

${ }^{105}$ T. Maezawa et al., Dependence of filler size on space charge formation in LDPE/MgO under high electric field at high temperature, Int. Symp. Electrical Insulating Materials, 2008. (ISEIM 2008) (IEEE, 2008), pp. 139-142.

${ }^{106}$ J. Wu, W. Liu, Y. Zheng, Q. Wang and Y. Yin, Effect of nanoadditive size on the space charge behaviour in $\mathrm{LDPE} / \mathrm{SiO}_{2}$ nanocomposite, 2010 10th IEEE Int. Conf. Solid Dielectrics (ICSD) (2010), pp. 1-4.

${ }^{107}$ J. Gao, X. Zhou, L. Sun, T. Zhang and X. Zhang, Study on space charge behaviour in polyethylene doped with nano-montmorillonite, 2013 IEEE Int. Conf. Solid Dielectrics (ICSD) (IEEE, 2013), pp. 843-846.

${ }^{108}$ B. Han et al., Study on space charge distribution in Low-density polyethylene (LDPE)/Zeolite nanocomposite in PEA method, 2013 IEEE Conf. Electrical Insulation and Dielectric Phenomena (CEIDP) (IEEE, 2013), pp. 691-694.

${ }^{109}$ X. Chi, J. Gao, J. Guo, G. Zheng and X. Zhang, Research on interface modification and electrical tree of PE/MMT composites, 2013 IEEE Conf. Electrical Insulation and Dielectric Phenomena (CEIDP) (IEEE, 2013), pp. 527-530.

${ }^{110}$ Y. Yin, X. Dong, Y. Wang, Q. Wang and X. Li, Charge carrier transportation in the composite of Nano-MgO and cross-linking polyethylene, IEEE 9th Int. Conf. Properties and Applications of Dielectric Materials, 2009. ICPADM 2009 (IEEE, 2009), pp. 761-764.

${ }^{111}$ Y. Kim, Y. Cha, K. Lim, J. Nam and G. Lee, Electrical insulation evaluation of crosslinked polyethylene nanocomposite blended with $\mathrm{ZnO}, 2012$ Int. Conf. Condition Monitoring and Diagnosis (CMD) (2012), pp. 1242-1245.

${ }^{112} \mathrm{M}$. Abou-Dakka and L. Cisse, Evolution of some dielectric properties of polypropylene-nanoclay composites with DC poling, 2011 Annual Report Conf. Electrical Insulation and Dielectric Phenomena (CEIDP) (IEEE, 2011), pp. 628-631.

${ }^{113}$ C. Calebrese, J. K. Nelson, L. S. Schadler and D. Schweickart, Polyamideimide-alumina nanocomposites for high-temperatures, 2010 10th IEEE Int. Conf. Solid Dielectrics (ICSD) (IEEE, 2010), pp. 1-4

${ }^{114}$ Q. Wang, G. Chen and A. S. Alghamdi, Influence of nanofillers on electrical characteristics of epoxy resins insulation, 2010 10th IEEE Int. Conf. Solid Dielectrics (ICSD) (IEEE, 2010), pp. 1-4.

${ }^{115}$ W. Qi, P. Curtis and G. Chen, Effect of nano-fillers on electrical breakdown behavior of epoxy resin, 2010 Annual Report Conf. Electrical Insulation and Dielectric Phenomena (CEIDP) (2010), pp. 1-4.

${ }^{116} \mathrm{Z}$. Xu, M. Reading, A. Vaughan and P. Lewin, Space charge distribution in filled epoxy composites containing micro and nano fillers, 2011 14th Int. Symp. Electrets (ISE) (IEEE, 2011), pp. 117-118.

${ }^{117} \mathrm{~B}$. Han et al., Space charge distribution in Low-density Polyethylene (LDPE)/Pumice composite, IEEE 9th Int. Conf. Properties and Applications of Dielectric Materials, 2009. ICPADM 2009 (IEEE, 2009), pp. 969-972.

${ }^{118}$ D. Fabiani, G. C. Montanari, A. Krivda, L. E. Schmidt and R. Hollertz, Epoxy based materials containing micro and nano sized fillers for improved electrical characteristics, 2010 10th IEEE Int. Conf. Solid Dielectrics (ICSD) (2010), pp. 1-4.

${ }^{119} \mathrm{C}$. Wu, W. Yan and B. Phung, Influence of plasma-treated nanoparticles on space charge accumulation in epoxy resin insulation, 2013 IEEE Conf. Electrical Insulation and Dielectric Phenomena (CEIDP) (IEEE, 2013), pp. 784-787.

${ }^{120}$ Y. Wei, B. T. Phung, H. Zhao Jun and K. Ostrikov, Plasma polymer-coated on nanoparticles to improve dielectric and electrical insulation properties of nanocomposites, IEEE Trans. Dielectr. Electr. Insulat. 21, 548 (2014). 